\title{
NORMAS TRIBUTÁRIAS INDUTORAS E O FOMENTO DA ECONOMIA CRIATIVA PARA O DESENVOLVIMENTO DO NORDESTE BRASILEIRO
}

\section{TAX-INDUCED AND PROMOTION OF THE CRIATIVE ECONOMY FOR DEVELOPMENT OF BRAZILIAN'S NORTHEAST}

\author{
${ }^{1}$ Evilásio Galdino de Araújo Júnior \\ ${ }^{2}$ Patrícia Borba Vilar Guimarães
}

\section{RESUMO}

O presente artigo propõe uma reflexão acerca do papel das normas tributárias indutoras no cenário político e econômico brasileiro, com ênfase no objetivo constitucional de promoção do desenvolvimento e minimização de desigualdades. Utiliza-se como aporte teórico a doutrina do Direito e Desenvolvimento e a caracterização do Estado brasileiro como Regulador da Economia. Como recorte empírico, analisa-se índices econômicos da região Nordeste e sua complexa relação entre PIB e IDH. Por fim, propõe-se que a indução tributária não seja o epicentro da política econômica de desenvolvimento, mas uma ferramenta de um projeto econômico sustentável: a Economia Criativa

Palavras-chave: Constituição, Indução tributária, Desenvolvimento, Economia Criativa, Nordeste

\begin{abstract}
This article proposes thinking about the tax-induced's importance in the Brazilian's politic and economy context, the relating between tax-induced, development and the power to reduce inequalities. It is based on the theory of Law and Development, and Regulatory State. This paper approaches the issue with an empirical focus in the Brazilian's Northeast index, particularly the relationship between the Human Development Index and Gross Domestic Product per capita. Finally, we propose the tax-induced no more in the center of political economy to development, but it can be an important tool for a sustainable economy, especially for enable the Creative Economy
\end{abstract}

Keywords: Constitution, Tax-induced, Development, Creative Economy, Northeast

\footnotetext{
${ }^{1}$ Mestrando em Direito pela Universidade Federal do Rio Grande do Norte (UFNR), Natal, Rio Grande do Norte, Brasil. Administrativo pela Universidade Estadual do Rio Grande do Norte (UFNR), Natal, Rio Grande do Norte, Brasil. Email : evi_jr@hotmail.com

${ }^{2}$ Doutorado em Recursos Naturais pela Universidade Federal de Campina Grande (UFCG) Campina Grande, Paraíba, Brasil. Mestre em Direito pela Universidade Federal do Rio Grande do Norte (UFNR), Natal, Rio Grande do Norte, Brasil. Professora Docente pela Universidade Federal do Rio Grande do Norte (UFNR), Natal, Rio Grande do Norte, Brasil. Email: tutortreinamento@ gmail.com
} 


\section{INTRODUÇÃO}

Em tempos de crise econômica é comum haver um verdadeiro vendaval de críticas e alternativas a respeito da política econômica que o país deve adotar. Posições contrárias a intervenção estatal nos diversos setores se misturam ao seu oposto. No centro do problema está a estagnação social e a dúvida de qual caminho seguir. Nesse cenário, entender a realidade em sentido aprofundado e a partir daí propor uma reflexão jus-sociológica faz-se de fundamental importância para a mudança paradigmática.

O Constituinte de 1988 positivou no artigo $3^{\circ}$ a preocupação com a garantia do desenvolvimento nacional (inciso II) em prol do fim da pobreza e redução das desigualdades sociais e regionais (inciso III). Através da leitura do mencionado artigo, observam-se os objetivos que devem delinear todo o ordenamento pátrio, envolvendo o desejo de seguir e o comprometimento de direcionar ações para que se alcance a concretude tais objetivos. A não realização acarreta prejuízo direto aos fundamentos do Estado, principalmente à dignidade da pessoa humana - esse considerado como o epicentro ou super fundamento do ordenamento.

A dignidade da pessoa humana passa, dentre outros aspectos, pela impossibilidade dos cidadãos viverem abaixo de um mínimo existencial, em estado de miserabilidade, flagelo ou degradação, tendo assegurado seus direitos fundamentais e com a possibilidade de viver e interagir dignamente nas relações sociais.

Orbitando o fundamento central no artigo $1^{\circ}$ da Constituição, estão previstos, também, os valores sociais do trabalho e da livre iniciativa, ambos como métodos de aquisição de emancipação financeira e garantia do mínimo existencial. Dessa forma, no contexto de sociedade capitalizada, a concretude de tais objetivos passa pela fundamental estruturação econômica do Estado.

Nesse aspecto a Constituição define, no título VII "Da Ordem Econômica e Financeira", limites e garantias à iniciativa privada para atuar no mercado nacional, bem como estabelece os parâmetros de controle e atuação do Estado no segmento, traçando o equilíbrio de forças o qual deve resultar no desenvolvimento econômico com reflexo direto na ideia de justiça social e existência digna. 
O constituinte ao estabelecer as balizas que norteiam as relações econômicas trouxe a nodal evidência de que a ordem vigente até então não servia para os anseios da sociedade brasileira e que novos caminhos precisariam ser tomados no sentido de fazer da economia um vetor para o alcance dos objetivos constitucionais. Assim, o artigo 170 elenca os princípios que dão legitimidade às relações econômicas, garantindo a viabilidade da iniciativa privada pautada na responsabilidade do capital.

Nesse contexto, a atuação do Estado foi limitada para impedir a intervenção desnecessária nas relações econômicas, vindo a inviabilizar a prática empresarial no País. Em contrapartida, há a necessidade que sejam adotadas medidas que garantam o acesso aos direitos sociais, através das políticas públicas. Sendo assim, ao Estado compete o papel de direção dos rumos econômicos do país, intervindo na economia, ora como agente econômico, ora como agente normativo e regulador das atividades econômicas.

A tributação é, nesse aspecto, importante elemento de interação econômica, visto que por se tratar da principal fonte de receita do Estado, repercute diretamente no fluxo financeiro do mercado e na vida dos cidadãos - gerando facilidades ou obstáculos para determinados sujeitos.

O Estado no papel/poder de regulador da economia induz os agentes econômicos a certos comportamentos, utilizando-se, muitas das vezes, da própria tributação para determinado fim - é a vertente extrafiscal da tributação.

Sob esse prisma, o presente artigo propõe uma reflexão acerca do papel das normas tributárias indutoras no cenário político e econômico brasileiro atual, com ênfase na promoção do desenvolvimento humano, nos moldes da doutrina de Amartya Sen e dos teóricos do Direito e Desenvolvimento.

Atrelado à pressuposição explícita de um desenvolvimento social e econômico historicamente caótico, está o problema de que políticas públicas adotam, por vezes, estratégias econômicas desconexas com os reais objetivos constitucionais de desenvolvimento, pautando-se em padrões métricos da economia tradicional, muito centrada no que decorre do produto interno bruto (PIB), sobrepondo, por exemplo, a renda per capta em detrimento da análise de índices de desenvolvimento humano. 
Além disso, muito pelo histórico agroexportador, têm-se um cenário econômico centrado em commodities - o que não é exclusividade do Brasil, mas de muitos países, advindo da ótica industrial de utilização de bens tangíveis e esgotáveis, escassos. Isso contribui substancialmente para o quadro de desequilíbrio e dependência financeira dentre as regiões. O desafio sob o aspecto do desenvolvimento é o de como contornar o paradigma apresentado e empoderar as regiões a romperem com o vicioso sistema de dependência de repasses financeiros.

Em 2011 o Ministério da Cultura criou a Secretaria da Economia Criativa e lançou um plano de gestão relativo ao período de 2011 a 2014. Essa ação parte da tentativa de fomentar um caminho alternativo para a economia nacional, buscando aproximar as políticas econômicas do centro gravitacional das características das culturas locais, na esteira do que vem ocorrendo mundialmente - países como Austrália, Inglaterra, Noruega e Dinamarca.

A viabilização da estratégia de Economia Criativa aplicável no país está atrelada a alguns marcos de sustentação, ou seja, é necessário que haja a fluência de diversas áreas para se efetivar uma política pública eficiente nesse sentido. Portanto, o estudo proposto visa examinar o papel da tributação na estrutura Constitucional, sob o recorte de instrumento propulsor da Economia Criativa e, consequentemente, de desenvolvimento econômico regional.

No primeiro momento, tratar-se-á do núcleo econômico na Constituição Federal à luz da teoria do Direito e Desenvolvimento. Dessa forma, poder-se-á estabelecer a real compreensão a respeito da real dimensão do que a doutrina denominou de Constituição econômica e de que forma o Estado pode diretamente intervir na economia e seus limites.

Posteriormente, buscar-se-á entender o que são normas tributárias indutoras, seu papel no federalismo fiscal e a amplitude de sua importância frente ao contexto econômico atual. Por fim, direcionar-se-á o arcabouço teórico para a repercussão prática, do desenvolvimento regional por meio do empoderamento da economia cultural. Se opta por uma reflexão aplicada à região Nordeste brasileira, tendo em vista suas particularidades culturais, a realidade social e a forma como tem se destacado nos números econômicos do país nos últimos anos. 


\section{DO ESTADO LIBERAL À UMA PERSPECTIVA DESENVOLVIMENTISTA}

Em primeiro momento, tem-se que o Estado de Direito adveio da luta entre a liberdade e absolutismo. O grande marco é a Revolução Francesa de 1789 que, imbuída de ideais de liberdade, igualdade e fraternidade, rompe com a ordem vigente e estabelece um Estado pautado em leis, iniciando o processo de constitucionalismo.

O Constitucionalismo em sua exegese está diretamente associado à concepção de garantias aos direitos individuais, no fito de proteger os homens dos arbítrios do poder central. Nessa esteira percebe-se que em sua origem, embora com o embrião do conceito de direitos sociais no processo de indignação revolucionária, o conceito é tipicamente liberal. Isso se deve ao fato da ideologia sócio-política que dominou o séc. XIX, o laissez faire (expressão símbolo do liberalismo econômico), na qual a liberdade política deveria bastar para impedir as desigualdades sociais.

Ocorre que o Estado mínimo e a liberdade, aliado ao contexto de revolução industrial, culminou em um abismo social entre burguesia e proletariado, no qual direitos como educação, trabalho, e saúde eram inexistentes no âmbito comum. Sobre esse período, vide as palavras de Paulo Bonavides:

\footnotetext{
Mas, no momento em que se apodera do controle político da sociedade, a burguesia já se não interessa em manter na prática a universalidade daqueles princípios, como apanágio de todos os homens. Só de maneira formal os sustenta, uma vez que no plano de aplicação política eles se conservam, de fato, princípios constitutivos de uma ideologia de classe. [...]. Antes, o político (o poder do rei) tinha ascendência sobre o econômico (o feudo). Depois, dá-se o inverso: é o econômico (a burguesia, o industrialismo), gerando uma das mais furiosas contradições do século XIX: a liberal-democracia. (BONAVIDES, 2007, p. 42 e 55).
}

A partir do surgimento dos primeiros sindicatos e de ideologias fundadas na análise histórica das relações de poder atrelada ao capital, a destacar os autores Karl Max e Engels e os primados de Hegel, aliado ao caos econômico que alguns países viviam, percebeu-se que era necessário que o Estado tivesse uma atuação mais ativa, estabelecendo mecanismos jurídicos que garantissem direitos básicos ao povo e mantivesse o equilíbrio e estabilidade econômica. Nesse sentido, Pablo Verdú (1975): 
[...] o Estado de Direito, que já não poderia justificar-se como liberal, necessitou, para enfrentar a maré social, despojar-se de sua neutralidade, integrar, em seu seio, a sociedade, sem renunciar ao primado do Direito. O Estado de direito, na atualidade, deixou de ser formal, neutro e individualista, para transformar-se em Estado Material de Direito, enquanto adota uma dogmática e pretende realizar a justiça social. (apud SILVA, 2008, p. 115)

Dessa forma, essa passagem paradigmática adicionou aos direitos fundamentais os de natureza social, econômico e cultural. Essas garantias passam a ganhar força constitucional a partir das constituições como a mexicana de 1917 e a alemã de 1919 (Weimar), daí surge a ideia de "constitucionalismo social" do séc. XX, sendo a regulação econômica uma consequência necessária desse processo, o que leva parte da doutrina, ao tratar desse enfoque, chamar de Constituição Econômica ${ }^{3}$.

Sobre esse momento na América Latina, Roberto Gargarela destaca:

Como consequência da mobilização da classe trabalhadora contra a desigualdade e o autoritarismo crescentes, a Constituição proclamou uma extensa e robusta lista de direitos. A diferença de outras constituições da época, tinha um forte compromisso com os direitos sociais, inclusive com os direitos a alimentação e a educação. De fato, a Constituição mexicana foi pioneira no desenvolvimento de um constitucionalismo mais social. [...]. A maioria dos países da região seguiram o exemplo do México, incluindo em suas constituições listas similares de direitos sociais. Deste modo, as constituições latinoamericanas refletiram e reforçaram o surgimento da classe trabalhadora como ator político e econômico chave na primeira metade de século XX. (GARGARELA, 2014, p. 9-10).

Com a ideia de Constituição Econômica, vem uma nova ótica acerca da forma como as cartas constitucionais passam a interagir com a economia, essas deixam de apenas respaldar a ordem existente, passando a alterá-la e moldá-la aos anseios sociais que se objetiva. Dessa forma, rompem com a ideia de mercado autorregulado, autossuficiente, onde ao Estado era relegado o papel meramente observador e legitimador do direito de propriedade privada.

As Constituições Econômicas do século XX buscam a configuração política do econômico pelo Estado. Desse modo, a característica essencial da atual Constituição Econômica, uma vez que as disposições econômicas sempre existiram nos textos, é a previsão de uma ordem econômica programática, estabelecendo uma Constituição Econômica diretiva, no bojo de uma Constituição Dirigente. (BERCOVICI, 2005, p. 34).

\footnotetext{
${ }^{3}$ Vide nesse sentido: BERCOVICI, Gilberto. Constituição econômica e desenvolvimento: uma leitura a partir da Constituição de 1988. São Paulo: Malheiros Editores, 2005; TAVARES, André Ramos. Direito
}

Constitucional Econômico. 2 Ed. São Paulo: Saraiva, 2003. 
De acordo com Canotilho (2005, p. 224 - 225), no âmbito das constituições dirigente tem-se que a legitimação material de todo o ordenamento se insere no texto constitucional. Nesse sentido, racionalizam-se os fenômenos político-sociais, ou seja, a mudança material passa fundamentalmente pelo Direito. Além disso, a direção também afeta a prospecção de intenções futuras, passando a delinear metas sociais a serem alcançadas.

Sob esse aspecto, observa-se a Constituição brasileira de 1988 como dirigente, a destacar o seu art. $3^{\circ}$, o qual é positivado no texto maior a identidade principiológica que o Estado assume perante e para a sociedade. Dessa forma, a exegese de todo o ordenamento é pautada nessa "cláusula transformadora", conforme denomina Pablo Lucas Verdú (1984, p. 190-198) ao destacar o caráter que esse tipo de dispositivo tem quando contrasta a realidade social vigente e a necessidade de modificá-la.

Ao observar sob o enfoque de Constituição Econômica, nota-se que o mencionado artigo aponta a linha teleológica para qual a economia nacional deve ser agendada: contribuir para o desenvolvimento nacional, erradicar a pobreza e reduzir as desigualdades sociais e regionais. Vale destacar que isso não impede o natural fluxo de capital e lucro - vide o inciso IV do artigo $1^{\circ}$, no qual um dos fundamentos do Estado Democrático de Direito é a livre iniciativa e o livre trabalho - mas canaliza o processo de mercado para um direcionamento finalístico constitucional, ou seja, ao invés de mercado autossustentável e autossuficiente do liberalismo, há a perspectiva de mercado responsável.

No título VII da Constituição da República Federativa do Brasil, no artigo 170, inicialmente, fica reiterado que a ordem econômica se funda na valorização do trabalho humano e na livre iniciativa, tendo como finalidade a vida digna e socialmente justa. Para isso, o dispositivo trás os princípios pelos quais o mercado deve se pautar dentro de sua liberdade mitigada

Contudo, parte da doutrina critica o texto constitucional por entender que para que haja efetivação dos objetivos, seria necessário que a CRFB/88 trouxesse normas de aplicação imediata, nas quais o constituinte disciplinasse direta e imediatamente os meios para alcançar os fins intencionados. Dessa forma, a carga programática da ordem constitucional é considerada como uma das razões de ineficiência de alguns setores políticos no intuito de 
concretização dos ditames. José Afonso da Silva conceitua essas normas com as seguintes palavras:

\begin{abstract}
Normas constitucionais através das quais o constituinte, em vez de regular, direta e indiretamente, determinados interesses, limitou-se a traçar os princípios para serem cumpridos pelos seus órgãos (legislativos, executivos, jurisdicionais e administrativos), como programas das respectivas atividades, visando à realização dos fins sociais do Estado. (SILVA, 2012, p. 138).
\end{abstract}

Não obstante, Bercovici (2005, p. 42-43) explica que para conhecer a real dimensão das normas constitucionais é preciso que não se limite apenas ao aspecto da juridicidade, sendo um erro limitar a interpretação da norma apenas sob o prisma de uma Constituição autocentrada em si, pois é impossível realizar uma mudança fática na sociedade apenas por meio dos dispositivos constitucionais. Para o autor, antes de haver o descrédito da carta magna, deve-se observar a inter-relação com o contexto sociológico, histórico, econômico e político, só assim poderá se extrair suas múltiplas funções.

Fundamentando sua tese, o autor cita a teoria das funções constitucionais propostas por Hans Peter Scheneider, no sentido de que a dimensão democrática (formação de unidade política), a dimensão liberal (coordenação e limitação do poder estatal) e a dimensão social (configuração social das condições de vida), observadas em conjunto, geram aspectos fundamentais para se obter a superação dos obstáculos de concretude plena dos objetivos, em especial o fomento ao desenvolvimento econômico (SCHENEIDER apud BERCOVICI, 2005, p. 42).

Sendo assim, antes de adentrar na explicação da inter-relação sistêmica que a Constituição promove entre o Estado tributante e ao mesmo tempo regulador da economia, faz-se necessário compreender o que vem a ser a perspectiva desenvolvimentista que o mencionado art. $3^{\circ}$ da Constituição impõe no ordenamento. Para isso, necessário contextualizar o aspecto econômico sob o prisma da teoria do Direito e Desenvolvimento.

\title{
2.1 A CONSTITUIÇÃO BRASILEIRA À LUZ DA TEORIA DO DIREITO E DESENVOLVIMENTO
}


O Direito e Desenvolvimento consiste em uma perspectiva teórica que retoma a década de 1950, mais especificamente o programa de boa governança (GUIMARÃES, 2013, p. 8). Nos dias cotidianos é tido como uma aplicação do "rule of law" (Estado de Direito), relacionando-se como suporte jurídico-institucional para a promoção do desenvolvimento econômico nos Estados nacionais (BRESSER-PEREIRA, 2006). Tal tratamento remete ao direito como uma das estruturas fundantes na sustentação da sociedade contemporânea, a ser necessariamente no contexto de formação econômica, cultural e política das nações (NUSDEO, 2010).

A caracterização do espaço teórico de atuação do Direito e Desenvolvimento toma como referência as teorias neoinstitucionalistas, aproximando o direito e a economia. Dessa maneira, como critério de medição de eficiência se ampara na métrica da análise econômica do direito e suas premissas (rejeição da autonomia do direito perante a realidade social e econômica; utilização de métodos de outras áreas do conhecimento, tais como economia e filosofia; crítica à interpretação jurídica como interpretação conforme precedentes ou o direito, sem referência ao contexto econômico e social).

Trubek e Santos (2006a) sugerem que o Direito e Desenvolvimento surge da interação de três vertentes: economia, instituições e leis. Essa seria a caracterização da terceira fase da teoria, alcançada a partir de 1990, onde a economia influencia as práticas e políticas institucionais das agências de desenvolvimento, mas estas políticas e práticas podem também ser levadas em conta na formulação da teoria econômica. Dessa maneira, há uma área de sobreposição entre prática institucional e a teoria econômica. (GUIMARÃES, 2013, p. 16).

Partindo dessa relação, os autores passam a esquematizar as três fases do direito e desenvolvimento. Aqui se opta por concentrar esforços na terceira fase, a que afeta diretamente a concepção de desenvolvimento presente na Constituição brasileira de 1988. Não obstante, explica-se sinteticamente as anteriores como forma de demonstrar que a concepção de Estado se liga diretamente, historicamente, com a visão econômica que se tem da teoria.

A primeira fase, conhecida como "Movimento Direito e Desenvolvimento", é marcada pela relação com a visão econômica keneysiana, onde se buscava o fomento do consumo e crescimento. Nesse momento histórico, que perdura até a crise econômica mundial da década de 1970 - crise do petróleo e crise do padrão monetário internacional -, 
incentivava-se a circulação de capital, quanto mais o Estado promove-se a circulação mais retorno teria. Nesse sentido, em situações de recessão por falta de investimentos, era salutar o Estado fazer as vezes de investimento privado, incrementando investimentos em áreas estratégicas (FARIA, 2000, p. 113-114).

A segunda fase, conhecida como "Law and neoliberal Market", é marcada por uma mudança de perspectiva, o Direito é visto como instrumento para fomentar transações privadas; protege-se o direito privado e assegura-se a aplicabilidade dos contratos; prega-se um Estado menos presente no monopólio econômico, atuando de modo a garantir padrões de igualdade entre capital interno e estrangeiro; facilitação dos mercados. Esse modelo está muito associado ao período do final dos anos 1970 e início da década de 1990, onde a ótica "neoglobalizadora" passa a influenciar os mercados globais.

A terceira fase, classificada por Trubek e Santos como "Comprehensive Framework for Development", apresenta cinco pontos essenciais, conforme elenca Patrícia Borba Vilar Guimarães (2013, p. 17): 1) Leis transplantadas podem produzir resultados diversos do previsto pelos agentes externos; 2) Sucesso das políticas econômicas não pode ser desconexo do contexto local; 3) Desenvolvimento não é meramente redução de pobreza; 4) Reconhecimento dos limites dos mercados e expansão da definição de desenvolvimento; 5) Novos modelos abrangentes de desenvolvimento.

A terceira fase, pode-se dizer que é um misto do que teoricamente há de melhor na concepção liberal e social, extrai-se o que se solidificou como coerente para o avanço humano e une em um meio termo, onde, do ponto de vista da relação Estado-economia, há a liberdade necessária ao mercado e ao mesmo tempo há o direcionamento para o cumprimento de metas sociais que o Estado busca. Nesse sentido, surge o Estado Regulador.

Sobre o conceito de Regulação, aponta Vladimir França (2014, p. 21):

Outra possibilidade é ver regulação como a intervenção do Estado no domínio econômico, com vistas à concretização de finalidades específicas, reputadas de interesse público. Entretanto, não se pode perder de vista que esse termo - tal como regulador - tem sido empregado para designar as atuações estatais no domínio social. Ademais, dificilmente uma medida estatal no campo social deixa de ter impacto no campo econômico, e vice-versa, no Estado democrático de Direito. 
Aprofunda-se o tema do Estado Regulador enquanto concepção da terceira fase da teoria do Direito e Desenvolvimento e sua relação com o cenário brasileiro sob a ótica da Constituição de 1988.

\subsection{A RELAÇÃO ENTRE O ESTADO REGULADOR E A TRIBUTAÇÃO INDUTORA}

Partindo da premissa de que a Constituição cria subsistemas interligados, que dialogam para o fim de concretizar seus objetivos, faz-se, portanto, visceral a relação entre economia e tributação nesse processo de busca pelo desenvolvimento. Para tanto, é preciso entender a tributação de uma forma mais abrangente, não apenas como normas de arrecadação de receita positivadas, mas relacionando-se diretamente com os estudos técnicos da economia, sociedade e direitos econômico, nesse ponto a escola do Law and Economics (lei e economia) traz significativa contribuição ao romper com a visão utilitarista do direito e propor um estudo dialético.

Ao Estado é atribuído o poder de estabelecer regras, de dirigir e governar, nesse sentido, o tributo surge como ferramenta de fundamental importância no sentido incentivar ou inibir determinados comportamentos. Nessa linha, afirma André Elali:

[...] a tributação surge como alternativa do Estado para fomentar o desenvolvimento nacional, cujo conceito deve abarcar de forma especial a redução das desigualdades regionais e sociais. Através de normas tributárias, pode e deve o Estado induzir os agentes econômicos à prática daqueles comportamentos desejáveis na busca da ordem econômica proposta no plano da Constituição. (ELALI, 2007, p. 41)

Portanto, a tributação tem importante papel de indução sobre a economia nacional. Dessa forma, através de incentivos fiscais ou onerações o Estado direciona os agentes econômicos a um determinado caminho

Ocorre que o Estado ao regular a economia do país deve levar em consideração sua extensa dimensão e as desigualdades regionais e sociais, só assim poderá estabelecer políticas tributárias justas e com efeitos concretos, isonômicas - tendo em mente a filosofia aristotélica de igualdade. A problemática se dá em como equacionar as diversas realidades, como se certificar que o efeito será o desenvolvimento - afinal está se falando em renúncia de receitas, onde em última análise são os cidadãos que estão a arcar com a ausência de arrecadação. 
Nesse instante é que se mostra importante a reflexão da teoria do risco de Ulrich Beck $^{4}$, pois ao se considerar as desigualdades regionais identificam-se localidades com vários estágios de modernidade - embora haja pontos de intercessão lógicos - e, dessa forma, a adoção de modelos genéricos, apenas atraindo empresas transnacionais, ou conglomerados de grande porte, para áreas de baixo desenvolvimento não significa ter como resultado o progresso social do local, e muito menos do país. Na sociedade de risco, pós-tecnológica, mesmo quando as medidas adotadas atingem os seus resultados esperados pela concepção inicial, acabam por gerar efeitos secundários imprevistos.

O economista indiano Amartya Sen, uma das principais referências associadas à terceira fase do Direito e Desenvolvimento, na obra Desenvolvimento como liberdade, aponta um caminho que relaciona desenvolvimento como ideia inerente à promoção de liberdades substantivas, ou seja, não restrita a um aspecto de concentração de renda, mas de garantias fundamentais. Dessa maneira, a ótica apresentada em sua teoria de desenvolvimento eleva a amplitude da concepção de desenvolvimento muito além do aspecto puramente econômico, mas passando pelo papel do Estado nas relações de mercado, nas relações políticas, nas relações ambientais, nas garantias de isonomia, nas privações sociais. Todas essas vertentes de alguma maneira se afetam e interferem diretamente para a avaliação do estado de desenvolvimento.

$\mathrm{Na}$ teoria apresentada, a liberdades são princípio meio (papel instrumental) e fim primordial (papel constitutivo) para o alcance do desenvolvimento (SEN, 2010, p. 55). Essas liberdades são elencadas pelo autor em cinco tipos: (1) liberdades políticas, (2) facilidades econômicas, (3) oportunidades sociais, (4) garantias de transparência e (5) segurança protetora (SEN, 2010, p. 25).

Nessa perspectiva, o autor torna palpável e permite a avaliação qualitativa do desenvolvimento econômico, trazendo para a análise diversos elementos que são inerentes à existência humana digna, como, por exemplo o combate à fome, a educação e saúde para promoção de uma conscientização democrática e essa, por sua vez, vindo a afetar a forma de enxergar as relações sociais e estatais, em um processo encadeado.

\footnotetext{
${ }^{4}$ Vide em: BECK, U, Risk society. Towards a new modernity, 1992.
} 
Assim, muda a perspectiva e mudam-se os critérios de avaliação, conforme dito. $\mathrm{Na}$ teoria econômica, crescimento econômico é definido como a elevação do nível de riqueza da sociedade, represada pelo PIB ou concentração de renda. $\mathrm{O}$ desenvolvimento econômico, por seu turno, muda o centro de gravidade da concentração de renda para a qualidade do bemestar social. A partir de Sen (bem como pelo economista Mahbubul Haq), o enfoque ganha o aspecto humanista, criando-se o Índice de Desenvolvimento Humano (IDH) - esse pondera o PIB per capta (estimativa de renda por pessoa), a taxa de longevidade e o nível de educação (SEIXAS, 2014), esse é classificado de 0 a 1 e quanto maior, melhor a qualidade de vida.

A complexidade da atuação reguladora é latente, pois ao mesmo tempo em que se induz o aquecimento do desenvolvimento econômico de uma determinada região e desafoga a grande dependência do Estado, pode-se está tirando oportunidades e surtindo efeito negativo para o crescimento de outra região. É necessário que haja programação e critérios nesse processo.

Nesse sentido, o tópico seguinte apresenta o cenário prático dessa relação, para que em seguida se possa ter uma proposta de direcionamento do mecanismo regulador, atentando não só para o uso da ferramenta indutora tributária por si, mas como um método vetorial de solidificar uma economia sustentável, que busca o desenvolvimento na perspectiva abordada por este artigo e levando em consideração a diversidade brasileira.

\section{A PRÁtICA DA INDUÇÃO FISCAL E SUA REPERCUSSÃo NO DESENVOLVIMENTO REGIONAL BRASILEIRO: O NORDESTE COMO INSTRUMENTO DE ANÁLISE}

Celso Furtado (1973) explica o histórico da formação econômica brasileira e aloca na região Nordeste especial atenção. Historicamente a região foi tida como a "questão regional brasileira", em virtude dos efeitos da seca - tida como o grande causador de discrepância entre a região e o sul-sudeste do país. Os governos da primeira metade do século $\mathrm{XX}$ destinavam esforço para solucionar tal fator. Porém, o problema de desenvolvimento da região ia muito além do aspecto climático, estava relacionado à organização econômica regional inadequada ${ }^{5}$. Hans Singer (1962) em estudo na região detalhou que a estrutura

\footnotetext{
5 TAVARES, Hermes Magalhães. Desenvolvimento e dinâmica em Celso Furtado. Disponível em: https://goo.gl/Wa9Zor. Acesso em 12 de março de 2016. p. 104
} 
econômica de todo o país contribuía para o quadro, desde a falta de políticas públicas de incentivos fiscais, até a forma de industrialização do país a partir de 1930 e em especial com o plano Kubitschek (de 1956).

Nesse contexto, no final da década de 1950 se tinha o Nordeste como uma economia preponderantemente rural, agrícola, necessitando de reforma agrária e investimentos de industrialização. Em 1959 o presidente Kubitschek solicita relatório ao economista Celso Furtado e que se observou foi que o Nordeste se caracterizava por uma renda per capta de 100 dólares/ano, enquanto o Sul-Sudeste por uma renda de 340 dólares/ano - a economia nordestina equiparava-se a $1 / 3$ da economia da região mais industrializada do país. Além disso, constatou-se que "a seca é uma crise de produção de magnitude limitada", mas que vinha a assumir outro patamar de afetação em virtude de atingir a grande parte da população que dependia da "economia de subsistência".

Nesse diapasão cria-se a SUDENE (Superintendência do Desenvolvimento do Nordeste), com base do relatório mencionado estratégias em diversas áreas foram traçadas em várias frentes, no campo financeiro por meio de incentivos fiscais a empresas privadas (por exemplo, a redução de 50 de imposto de renda pessoa jurídica para reinvestimento nos projetos do Nordeste $)^{6}$.

Em 1964 o governo militar passa a vigorar no país, esse manteve a SUDENE, mas passou a delinear outro âmbito de liberdade, mais restrito, priorizando a industrialização sustentada em benefícios fiscais descontrolados, que se apoiava no crescimento do PIB da região (muito pela industrialização das metrópoles regionais), porém que pouco refletia no contexto de desigualdade social e regional do país.

Com a redemocratização e o contexto constitucional já explicado, tem-se a perspectiva de maior eficiência em tal política fiscal. Nas últimas décadas o PIB do Nordeste vem subindo gradativamente, no que tange a renda (entre 2001 e 2007 - período que se pode comparar com os números do último atlas de desenvolvimento humano), o rendimento

\footnotetext{
${ }^{6}$ Detalhado em: MOREIRA, Raimundo. Nordeste brasileiro: uma política regional de industrialização. Rio de Janiero: Paz e Terra, 1982.
} 
domiciliar per capta saiu de uma média (em reais) de 133,1019, em 2001, para 386,3609 em $2007^{7}$.

É imprescindível para a presente reflexão analisar os indicadores dos efeitos positivos que determinada política de incentivos fiscais ocasiona na região e no ambiente. A pergunta crucial é: está havendo desenvolvimento humano, há um crescimento sentido nas relações sociais ou o benefício trazido com a renúncia de receita é limitada a indicadores econômicos?

A resposta do questionamento é importante a fim de se ponderar o quão eficiente é a adoção da política de benefícios. Em outras palavras, deve-se observar se há a adoção de medidas proporcionais, se o processo é transparente e o conjunto é eficaz à finalidade constitucional. Essa preocupação vem norteando vários acórdãos do Tribunal de Contas da União $^{8}$ (TCU), que em estudo realizado pela equipe da Secretaria de Macroavaliação Governamental, acerca da concretude da aplicação do artigo 14 da LC 101/2000 (Lei de Responsabilidade Fiscal - LRF) chegou às seguintes conclusões:

\begin{abstract}
11.5 No que diz respeito ao caput do art. 14 da LRF, foi constatado que nem todas as proposições convertidas em lei apresentaram a estimativa do impacto orçamentário financeiro no exercício em que deva iniciar sua vigência e nos dois subsequentes, em razão de dificuldades de ordem técnica, como abordado pela RFB (...) 11.6 Com relação ao cumprimento do inciso I do art. 14, ao se analisarem projetos de lei e medidas provisórias que concedam ou ampliem renúncia de receita tributária, verificou- se que o dispositivo não é cumprido (...) 11.7 Passou-se, então, à análise quanto à observância do inciso II do art. 14. O exame dos benefícios tributários concedidos com base nesse inciso, em 2008, revelou que o Poder Executivo utilizou como medida de compensação tanto o excesso de arrecadação apurado no período como ajustes na programação orçamentária e financeira da despesa pública, o que contraria o disposto na LRF. Isso porque a listagem de medidas compensatórias que consta do inciso II é exaustiva, não cabendo interpretação extensiva para incluir outros instrumentos de compensação da renúncia de receitas (...) 11.12 Também foi observada a inexistência de uma sistemática adequada para as concessões de renúncias de receitas, não sendo evidenciados claramente os órgãos que participam do processo, nem as competências de cada um. (TC- 015.052/2009- 7, p. 21-22)
\end{abstract}

Por meio de tal estudo, constata-se a desconexão entre previsão legal e realidade legislativa e administrativa, o artigo 14 da LRF está posto justamente para frenar os traços de corrupção na gestão do erário e apresentar maior transparência à sociedade, por meio de

${ }^{7}$ Fonte: IBGE - dados individuais das PNADs de 2001 a 2007. Presente em: SANTOS, Ana Aracelly L. Desigualdade de renda no Nordeste no período recente, 2001-2007. 2009. 128f. Dissertação (mestrado em Economia) - Centro de Ciências Sociais Aplicadas. Universidade Estadual de Maringá, Paraná. 2009.

${ }^{8}$ Nesse sentido os Acórdãos: 747/2010-TCU-Plenário; 3.437/2012-TCU-Plenário; 3.137/2011-TCU-Plenário 
mecanismos de fiscalização. Contudo, vê-se que reiteradamente o TCU tem constatado e editado recomendações face ao quadro de descontrole sistêmico. Amartya Sen, usando como exemplo as sociedades africanas e asiáticas, alerta para uma realidade não muito distante:

\begin{abstract}
A prevalência da corrupção é justificadamente considerada uma das piores barreiras no caminho do progresso econômico bem-sucedido - como, por exemplo, em muitos países asiáticos e africanos. Um nível elevado de corrupção pode tornar ineficazes as políticas públicas e também afastar o investimento e as atividades econômicas de setores produtivos, direcionando-os às colossais recompensas de atividades ilícitas. Pode ainda encorajar - como já mencionado - o desenvolvimento de organizações violentas como a Máfia. (...) alguns sistemas de regulamentação encorajam a corrupção conferindo poderes discricionários aos altos funcionários que podem conceder favores a terceiros (...). Mesmo se tais regimes não fossem contraproducentes também em outros aspectos (como ocorre com muita frequência), o custo social da corrupção pode ser razão suficiente para evita-los. (SEN, 2010, p. 350-351)
\end{abstract}

O custo social da lacuna no critério adoção e controle das políticas de benefícios é latente - justamente pelo desvio da finalidade da essência de adoção de tais medidas - ao passo que os números econômicos mascaram a eficiência real, denotam desenvolvimento enquanto não se traduz no suprimento das reais necessidades de políticas econômicas locais.

A política de benefícios, assim, deixa de ser ferramenta vetorial de desenvolvimento, para ser um mecanismo simbólico de desenvolvimento fictício - como exemplo tem-se a diferença entre renda per capta e índice de desenvolvimento humano de regiões, no primeiro critério o Brasil está entre as dez melhores economias ${ }^{9}$, já no segundo ocupa a $79^{a}$ posição ${ }^{10}$.

O atlas de desenvolvimento humano no Brasil, elaborado pelo Programa das Nações Unidas para o Desenvolvimento (PNUD) em 2010 (a avaliação é de dez em dez anos) demonstra que o estado do Nordeste mais bem colocado é o Rio Grande do Norte, apenas na $16^{\mathrm{a}}$ colocação (contando os 26 estados e o distrito federal). O município do Nordeste melhor colocado ocupa a 76 a posição, é Fernando de Noronha, Natal (capital do Rio Grande do Norte, melhor colocado entre os estados) está na $320^{\mathrm{a}}$ posição ${ }^{11}$. A matriz de avaliação é: longevidade, renda e educação.

\footnotetext{
${ }^{9}$ Pauta-se no PIB. Fonte: FMI-WEO

${ }^{10}$ Disponível em: < http://www.pnud.org.br/Noticia.aspx?id=3909>. Acesso em 24 de setembro de 2016.

${ }^{11}$ Disponível em:< http://www.atlasbrasil.org.br/2013/pt/ranking $>$. Acesso em 24 de setembro de 2016.
} 
Tendo em vista a discrepância do quadro apresentado, onde a política de indução não corresponde ao desenvolvimento regional, seja em virtude de falhas na estratégia de concessão de benefícios físcais a empresas até problemas de fiscalização, chega-se à constatação de que uma política pautada no desenvolvimento humano não será sólida enquanto utilizar como pilar de sustentação o mecanismo de indução fiscal.

Explica-se a afirmação pelo fato de que o manejo tributário, seja para beneficiar ou reprimir condutas, sempre estará atrelado ao mecanismo financeiro de renúncia de receitas, o que leva a crer que precisa haver uma substancialidade maior, visualizando a sustentabilidade a longo prazo que justifique a estratégia da ferramenta da indução fiscal. Em outras palavras, a indução fiscal não pode ser a pedra angular, mas é peça importantíssima para o alcance do paradigma desenvolvimentista.

É na busca da referida substancialidade que a proposta do próximo item se faz salutar, passando a abordar aspecto da recente teoria de Economia Criativa e repercutindo a possível subsunção à teoria estudada até o momento neste artigo.

\title{
4 A ECONOMIA CRIATIVA E O DESENVOLVIMENTO REGIONAL POR MEIO DA CULTURA
}

Partindo da visão de desenvolvimento da teoria do Direito e Desenvolvimento, temse a porta aberta para a incorporação do que a partir de 2001, com a publicação de John Howkins $^{12}$, ficou conhecido como Economia Criativa. Trata-se de uma teoria que busca relacionar criatividade e economia. Duisemberg assim integra a economia criativa ao desenvolvimento:

\begin{abstract}
A economia criativa se baseia nos ativos criativos, potencialmente geradores de crescimento socioeconômico. De acordo com a definição adotada pela Conferência das Nações Unidas sobre Comércio e Desenvolvimento (Unctad), a economia criativa tem o potencial de fomentar o crescimento econômico, a criação de empregos e os ganhos de exportação, ao mesmo tempo em que promove a inclusão social, a diversidade cultural e o desenvolvimento humano. Ao abarcar aspectos econômicos, culturais, tecnológicos e sociais, a economia criativa tem ligações entrelaçadas com a economia geral nos níveis macro e micro, por isso, a dimensão de desenvolvimento. Já que a criatividade é a força motriz principal, e não o capital, a economia criativa parece ser uma opção viável e uma estratégia de desenvolvimento mais orientada a resultados para os países em desenvolvimento. (DUISENBERG, 2008, p. 10)
\end{abstract}

${ }^{12}$ HOWKINS, John, The Creative Economy: how people make money from ideas, 2001. 
Nesse sentido, em 2011 o Ministério da Cultura criou a Secretaria de Economia Criativa e editou um plano de ações referente ao período entre 2011 e 2014. A intenção apresentada é justamente aproxima o conceito de economia criativa para a realidade brasileira, encontrando na sua diversidade cultural a fonte de valor simbólico inesgotável, potencial à produção de uma economia voltada à realidade local, onde se busca soluções para problemas financeiros inerentes às comunidades por meio do próprio costume daquela localidade, atrelando isso às ferramentas de tecnologia e modernização do modelo de produção. Os princípios norteadores do plano de economia criativa para o Brasil são: a diversidade cultural, a sustentabilidade, a inovação e a inclusão social.

Dessa forma, condensando esses parâmetros e pensando sob o aspecto de circulação de capital e aquecimento de economias inertes no paradigma tradicional, tem-se um interessante caminho para o estudo que busca a aproximação da efetivação dos objetivos e garantias constitucionais.

Para se ter ideia, em estudo encomendado pelo Ministério da Cultura em 2008, sobre a cadeia de valor das indústrias criativas do Brasil, observou-se que o setor havia sido responsável por $21 \%$ (representando 7,6 milhões de pessoas) do total de empregos formais do país, o que representava em 16\% do PIB nacional (DUISENBERG, 2008, p. 55).

Em suma, o que se tem com a economia criativa é uma mudança estratégica na perspectiva de crescimento, parte-se de uma base de desenvolvimento linear para uma exponencial. Isso se dá pela característica de inesgotabilidade do valor cultural local e tem uma forte potencialidade de afetação no IDH, de maneira mais sólida do que em incentivos pontuais e periódicos. Essa repercussão ocorre principalmente por tratar como matéria os bens culturais, intangíveis, ou seja, é necessário um plano de compreensão aprofundado de realidades locais e imersão nas peculiaridades de determinado povo, ponderando fatores geográficos, por exemplo.

Dois exemplos que traduzem o aspecto mencionado são: o caso do melão e o das panelas de barro de goiabeiras, ambos no interior do Rio Grande do Norte ${ }^{13}$. Trata-se de

\footnotetext{
${ }^{13}$ Esses casos estão relatados em GUIMARÃES, Patrícia Borba Vilar; XAVIER, Yanko Marcius de Alencar (Org.). O direito da economia criativa: temas de desenvolvimento e propriedade intelectual. São Paulo: Editora Max Limonad, 2015.
} 
práticas históricas do cotidiano local, que tenderiam a serem menos frequentes com o decorrer do tempo e da modernização tecnológica das cidades menos urbanizadas, mas que passam a ter valor agregado e geral uma nova dinâmica regional.

Essa última atividade (o caso das panelas de barro de goiabeiras) foi estudada, também, em Vitória no Espírito Santo e tem-se a seguinte síntese do impacto da proteção jurídica da indicação geográfica com selo de procedência (integrante da matriz de implementação da economia criativa, da qual também faz parte a política tributária):

\begin{abstract}
A Indicação de Procedência permitiu a agregação de valor ao produto, estimulando sua produção e venda em todo o Brasil. Além disso, se tornou artigo essencial para a culinária dessa região, pois são imprescindíveis para a apresentação dos pratos regionais. Apesar de ser parte da tradição gastronômica do Espírito Santo há tempos, com o selo de IG as panelas ganharam reconhecimento nacional, o que implicou no crescimento considerável do turismo gastronômico daquela região e possibilitou que a comida capixaba se tornasse símbolo da cultura nacional (GIESBRECHT, 2011).
\end{abstract}

É, portanto, a Economia Criativa um importante ponto de direcionamento estratégico para que se atrele a matriz indutora tributária, sendo por meio Estados Criativos que se alcance o desenvolvimento humano objetivado no art. $3^{\circ}$ da Constituição Brasileira de 1988. Além disso, a partir do mento que as políticas públicas materializem o plano estratégico para a Economia Criativa, há, consequentemente, o aquecimento econômico de localidades que no atual contexto encontram-se dependentes financeiramente de repasses de outros entes, visto a baixa produção autônoma de receita, e isso se traduz na minimização de desigualdades regionais.

\title{
5 CONCLUSÃO
}

Pelo exposto, observa-se que a Constituição de 1988 ao elencar como objetivos fundamentais da República Federativa do Brasil o desenvolvimento nacional, a erradicação da pobreza e redução das desigualdades sociais e regionais, está positivando anseios caros a uma perspectiva social de direitos. Ao mesmo tempo, coloca no art. $1^{\circ}$, dentre os seus fundamentos os valores sociais da livre iniciativa, dessa forma estabelecendo o equilíbrio característico da terceira fase da teoria do Direito e Desenvolvimento.

Dessa forma, tem-se o Estado como perseguidor de objetivos sociais, mas de modo a não obstar o fluxo de mercado. Nesse papel configura-se como um Estado regulador. Diante 
desse quadro é indispensável que se compreenda a atividade do Estado de forma sistêmica, nesse ponto a atividade tributante do Estado transborda o papel arrecadador para ser conjugado conjuntamente à princípios de Ordem Econômica, sempre em busca dos objetivos que sustentam o campo teleológico do ordenamento pátrio.

Para que se possa entender a devida equação entre regulação por indução tributária para se chegar a um contexto de desenvolvimento humano e minimização de desigualdades sociais, faz-se imprescindível enxergar a forma como se dá a política de benefícios tributários no atual contexto - daí se observa graves problemas de critérios, concessões e fiscalização -, bem como a correlação entre PIB e IDH. Diante do confronto desses indicies, observou-se que o Brasil, em especial a região Nordeste, apesar de se destacar em um cenário pautado na análise do PIB, ainda se encontra em situação aquém do desenvolvimento desejado quando se parte para uma perspectiva de IDH.

Dessa maneira, percebe-se que uma economia que busca o desenvolvimento não pode ter na política de benefícios fiscais a sua essência estratégica, isso porque a falta de substancialidade a torna demasiadamente instável e refém de atos repletos de subjetivismo.

Nesse contexto, aparece o conceito de Economia Criativa como uma opção sustentável de substanciar a referida lacuna, de modo a se utilizar a indução fiscal como ferramenta dessa e consequentemente pavimentar uma estrada rumo ao desenvolvimento.

\section{REFERÊNCIAS}

BERCOVICI, Gilberto. Constituição Econômica e Desenvolvimento: uma leitura a partir da Constituição de 1988. São Paulo: Malheiros Editores, 2005.

BONAVIDES, Paulo. Do Estado Liberal ao Estado Social. $8^{\text {a }}$ Ed. São Paulo: Malheiros, 2007.

BRASIL. Ministério da Cultura. Plano da Secretaria da Economia Criativa: política, diretrizes e ações 2011-2014. Brasília, 2011. 
BRESSER-PEREIRA, Luis Carlos. O novo desenvolvimentismo e a ortodoxia convencional. São Paulo em Perspectiva, São Paulo, Fundação Seade, v. 20, n. 3, p. 5-24, jul./set. 2006.

CANOTILHO, José Joaquim Gomes. Canotilho e a Constituição dirigente. 2. ed. Rio de Janeiro: Renovar, 2005

DUISENBERG, Edna dos Santos. Economia criativa: uma opção de desenvolvimento viável?. In: REIS, Ana Carla Fonseca. (org.). Economia Criativa como estratégia para o desenvolvimento: uma visão dos países em desenvolvimento. São Paulo: Itaú Cultural: Garimpo de Soluções, 2008.

MARTINS, Ives Gandra da Silva; ELALI, André; PEIXOTO, Marcelo Magalhães Peixoto. (org.). Incentivos Fiscais: questões pontuais nas esferas Federal, Estadual e Municipal. São Paulo: MP Editora, 2007.

FARIA, José Eduardo. O Direito na Economia Globalizada. São Paulo: Malheiros Editores, 2000 .

FURTADO, Celso. Formação econômica do Brasil. São Paulo: Cia. Editora Nacional, 1973.

GARGARELLA, Roberto. Constitucionalismo Latino-Americano: a necessidade prioritária de uma reforma In Constituinte Exclusiva, Um outro sistema político é possível. Disponível em:http://www.plebiscitoconstituinte.org.br/sites/default/files/material/Livro\%20Juridico\%20 Constituinte\%20Exclusiva\%202014.pdf. Acesso em 23 de setembro de 2016

GUIMARÃES, Patrícia Borba Vilar; XAVIER, Yanko Marcius de Alencar (Org.). O direito da economia criativa: temas de desenvolvimento e propriedade intelectual. São Paulo: Editora Max Limonad, 2015.

GUIMARÃES, Patrícia Borba Vilar. Contribuições teóricas para o direito e desenvolvimento. Texto para discussão / Instituto de Pesquisa Econômica Aplicada. Brasília : Rio de Janeiro : Ipea, 2013. 
NUSDEO, Fábio. Curso de economia. Introdução ao direito econômico. 6 ed. Ed. Revista dos Tribunais.São Paulo. 2010.

MOREIRA, Raimundo. Nordeste brasileiro: uma política regional de industrialização. Rio de Janiero: Paz e Terra, 1982.

SANTOS, Ana Aracelly L. Desigualdade de renda no Nordeste no período recente, 20012007. 2009. 128f. Dissertação (mestrado em Economia) - Centro de Ciências Sociais Aplicadas. Universidade Estadual de Maringá, Paraná. 2009.

SEN, Amartya. Desenvolvimento como liberdade. Trad. de Laura Teixeira Motta. São Paulo: Companhia das Letras, 2010.

SEIXAS, Luiz Felipe Monteiro. Um exame sobre a relação entre tributação e desenvolvimento sob a ótica da teoria de Amartya Sen. XAVIER, Yanko Marcius de Alencar...[et al], org. Desenvolvimento, direito econômico e estrutura - série perspectivas jurídicas do desenvolvimento, vol. 3. Natal, RN: EDUFRN, 2014.

SILVA, José Afonso da. Curso de Direito Constitucional Positivo. 32. Ed. São Paulo: Malheiros Editores, 2008.

VERDÚ, Pablo Lucas. Estimativa y política constitucionales. Madrid: Sección de Publicaciones - Facultad de Derecho (Universidad Complutense de Madrid), 1984. 